\title{
Relationship between antioxidant capacity and total phenolic content of red, rosé and white wines
}

\author{
Neuza Paixão, Rosa Perestrelo, José C. Marques, José S. Câmara* \\ Centro de Química da Madeira, Departamento de Química, Universidade da Madeira, Campus Universitário da Penteada, 9000-390 Funchal, Portugal
}

Received 28 February 2007; received in revised form 30 March 2007; accepted 3 April 2007

\begin{abstract}
Phenolic compounds are one of the most important quality parameters of wines, since they contribute to wine organoleptic characteristics such as colour, astringency, and bitterness. Furthermore, several studies have pointed out that many show biological properties of interest, related to their antioxidant capacity. This antioxidant activity has been thoroughly studied and a wide variety of methods have been developed to evaluate it.

In this study, the antioxidant activity of commercial Terras Madeirenses Portuguese wines (Madeira Island) was measured by three different analytical methods: [1,1-diphenyl-2-picrylhydrazyl (DPPH) radical scavenging assay, 2,2'-azino-bis-(3-ethylbenzothiazoline-6sulfonic acid $\left(\mathrm{ABTS}^{+}\right)$) radical cation decolourisation, and ferric reducing/antioxidant power (FRAP) for the evaluation of reducing power $\left(P_{\mathrm{R}}\right)$ and correlate them with the total phenolic content determined with the Folin-Ciocalteu's reagent using gallic acid as a standard.

The total polyphenol concentration was found to vary from 252 to $1936 \mathrm{mg} / 1$ gallic acid equivalents (GAE). The antiradical activity varied from 0.042 to $0.715 \mathrm{mM}$ Trolox equivalents and the antioxidant capacity varied from 344 to $1105 \mathrm{mg} / 1$ gallic acid equivalents (GAE). For the reduction power we obtained $3.45-3.86 \mathrm{mM}$ quercetin equivalents.
\end{abstract}

(C) 2007 Elsevier Ltd. All rights reserved.

Keywords: Phenolic composition; Antioxidant activity; $\mathrm{ABTS}^{+}{ }^{+}$DPPH

\section{Introduction}

Phenolic compounds or polyphenols constitute one of the most numerous and widely distributed groups of substances in the plant kingdom with more than 8000 phenolic structures currently known (Harbone, 1980). Tea, mainly green tea, red wines, beers and other foods may have a very complex phenolic composition (Haslam, 1996). The most widely distributed phenolic components in plants are the hydroxycinnamic acids - $p$-coumaric, caffeic and ferulic acids (Fig. 1). They are products of the secondary metabolism of plants and arise biogenetically from two main primary synthetic pathways: the shikimate pathway (Fig. 2) and the acetate pathway. Their reactivity is due to the

\footnotetext{
* Corresponding author. Tel.: +351 291705112; fax: +351 291705149.

E-mail address: jsc@uma.pt (J.S. Câmara).
}

acidic character of the phenolic function and to the nucleophilic character of the benzene ring. Based on their carbon skeleton, polyphenols are classified in non-flavonoid compounds (stilbenes, hydroxycinnamic acids and benzoic acids) and flavonoid compounds (flavonols, flavones, flavanols and isoflavones). Grapes contain non-flavonoid compounds mainly in the pulp, while flavonoid compounds are located in the skins, seeds, and stems. The phenolic composition of wines is conditioned by the grape variety and by other factors that effect the berry development, such as soil, geographical location and weather conditions. The occurrence of these substances in wines is not only a consequence of their extraction from grapes during winemaking. Once grapes are crushed before the beginning of alcoholic fermentation, several condensation reactions which involve some of those molecules (especially anthocyanins, catechins and procyanidins) take place, resulting in the 
<smiles>Oc1cc(O)c2c(c1)OC(c1ccc(O)c(O)c1)[C@H](O)C2</smiles>

$(+)$-Catechin<smiles>O=C(O)C=Cc1ccc(O)cc1</smiles>

p-coumaric acid<smiles>Oc1cc(O)c2c(c1)O[C@H](c1ccc(O)c(O)c1)[C@H](O)C2</smiles>

(-)-Epicatechin<smiles>O=C(O)C=Cc1cc(O)c(O)c(O)c1</smiles>

Cafeic acid<smiles>[R]c1ccc(/C=C/OC(C(=O)O)C(O)C(=O)O)cc1O</smiles>

$\mathrm{R}=\mathrm{OH}$, Caftaric acid $\mathrm{R}=\mathrm{H}$, Coutaric acid $\mathrm{R}=\mathrm{OCH}_{3}$, Fertaric acid<smiles>O=C(O)c1cc(O)c(O)c(O)c1</smiles>

Gallic acid

Fig. 1. Classes of major polyphenolic compounds occurring in wines.

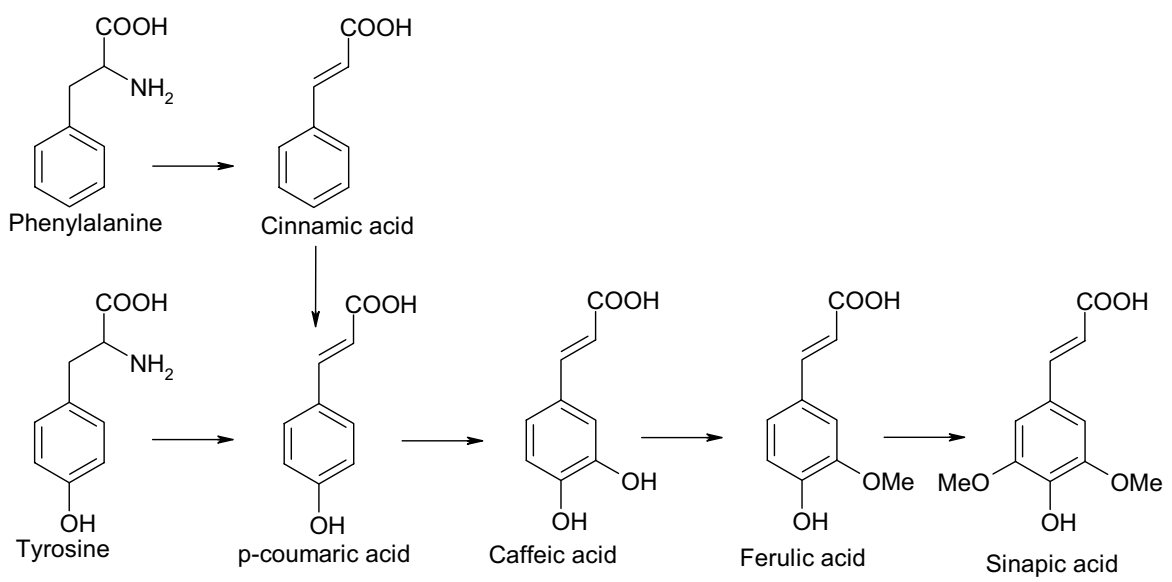

Fig. 2. Biosynthesis of the most widely distributed phenolic components via the shikimate pathway.

formation of new polymeric pigments which are responsible for important wine colour changes. Monagas, Bartolomé, and Gómez-Cordovés (2005) studied the chemical reactions and mechanisms involving phenolic compounds during winemaking, such as enzymatic, chemical oxidation and condensations reactions with a matrix-assisted-laserdesorption-ionization time-of-flight (MALDI-TOF) mass spectrometry technique allowing the identification of proanthocyanidin oligomers and polymers. This technique is suitable to determine the presence of molecules of higher molecular weight with high accuracy, and it has been applied with success to study procyanidin oligomers up to heptamers in the reflectron mode, and up to nonamers in the linear mode. Mass spectrometry, had and still has, a very important role for research and quality control in the viticulture and enology field, and its analytical power is relevant for structural studies on aroma and polyphenolic compounds. LC-MS allows the characterization of complex structures of grape polyphenols, such as procyanidins, proanthocyanidins, prodelphinidins, and tannins, and provides experimental evidence for structures that were previously only hypothesized. The LC-MS-MS method is also a very powerful tool in the study of anthocyanins and permits aglycone and sugar moiety characterization (Flamini, 2003).

On the other hand, winemaking techniques play an important role in the extraction of polyphenols from grapes and in their further stability in wines; the time of maceration and fermentation in contact with the grape skins and seeds, pressing, maturation, fining, and bottle aging are all factors that effect the phenolic composition on wines.

These compounds are one of the most important quality parameters of wines, since they contribute to wine organoleptic properties such as colour, astringency, bitterness and most of them may show biological properties of interest, related to their antioxidant properties. They have received much attention in the prevention of human neurodegenerative diseases such as cardiovascular disorders and cancer (Minussi et al., 2003). They are effective radical-scavengers with respect to oxygen free radicals and lipid peroxidation, which is determined by their reactivity as hydrogen- or electron-donating agents, the stability of the resulting antioxidant-derived radical and their metal chelation proper- 
ties. Polyphenols have also been reported to demonstrate antibacterial, antimutagenic, anti-inflammatory and vasodilatory actions (Estruch, 2000). This protective action may, in part, be associated with polyphenol compounds with antioxidant activity.

The moderate consumption of wine, especially red wine, has also recently been associated with the reduction in mortality from cardiovascular diseases, an effect that is commonly known as the "French Paradox" (Renaud \& De Lorgeril, 1992). The polyphenolic compounds present in wines, which are known to have a high antioxidant capacity, are the components recently attributed with providing the protective activity against these diseases. Hence the beneficial properties of wines have been mainly interpreted on the basis of the antioxidant properties on the flavonoid fraction, which are related to both free radical scavenging and transition metal chelating (Cao \& Prior, 2000). However, because of the different types of grapes used and the different production processes implemented, there are fundamental and crucial differences in white and red wine composition in terms of both the nature and quantity of polyphenols (Psarra, Makris, Kallithraka, \& Kefalas, 2002).

Recent investigations have stressed the importance of flavonols because of their importance in antioxidant potency and other biological activities (Makris, Kallithraka, \& Kefalas, 2006). Several methods are intensively study to determine antioxidant capacity. Stratil, Klejdus, and Kubáñ (2006) determined antioxidant activities by the Trolox equivalent antioxidant capacity (TEAC), DPPH (using diphenyl-p-picrylhydrazyl radical), and ferric reducing antioxidant power (FRAP) methods, from several species of commonly consumed vegetables. The values of content of phenolic substances and total antioxidant activity of the sets of samples correlate very well for all used methods. Very high values of antioxidant activity were found in intensely coloured vegetables.

To evaluate the impact of certain enological practices on antioxidant activity of wines, Villaño, FernándezPachón, Troncoso, and García-Parrilla (2006) applied oxygen radical absorbance capacity (ORAC), 2,2-azinobis-(3-ethylbenzothiazoline)-6-sulfonic acid (ABTS) and 1,1-diphenyl-2-picrylhydrazyl (DPPH). The information yielded can be used to obtain wines with maximum antioxidant capacity.

To improve the radical scavenging ability of polyphenolic compounds, Villaño, Fernández-Pachón, Moyá, Troncoso, and García-Parrilla (2007) used the DPPH method. $\mathrm{EC}_{50}$ and $\mathrm{TEC}_{50}$ parameters have been calculated. $\mathrm{EC}_{50}$ values are extremely diverse; $\mathrm{TEC}_{50}$ considers the rate of reaction towards the free radical. Antioxidant efficacy (AE) is a parameter that combines both factors. Compounds with a high $\mathrm{EC}_{50}$ value, could be considered as antioxidants with low relevance, but instead show the highest $\mathrm{AE}$ value of the phenolic compounds due to their fast rate of reaction, what is of great biological importance. Guendez, Kallithraka, Makris, and Kefalas (2005) also employed the stable radical DPPH for the determination of low molecular weight polyphenolic constituents in grape and correlate them with antiradical activity in order to obtain a detailed and analytical picture of the profile of principal low molecular weight polyphenols that occur in seeds.

They are several different methods to determine the antioxidant capacity. These methods differ in terms of their assay principle and experimental conditions. Most of them are based on the study of a reaction in which a free radical is generated and how this reaction is inhibited by the addition of the compound or sample which is the object of the measurement of antioxidant capacity. These antioxidant properties provide a rationale for exploring the polyphenol content of commercial wines to define those that are especially abundant in these desirable compounds and to stimulate the development of enological techniques for their enrichment (Alonso, Domínguez, Guillén, \& Barroso, 2002).

A rapid and simple method for estimating the antiradical activity of foods utilizes the stable free radical 1,1diphenyl-2-pycrylhydrazyl (DPPH') by the addition of scavenging compounds. This is one of a few stable and commercially available organic nitrogen radicals and shows a characteristic UV-Vis spectrum with a maximum absorbance close to $515 \mathrm{~nm}$. This is a method technically simple, but some disadvantages limit its applications. Many antioxidants that react quickly with peroxyl radicals may react slowly or may even be inert to DPPH and the reaction kinetics between DPPH and antioxidants are not linear to DPPH concentrations (Huang, Ou, \& Prior, 2005). The addition of an antioxidant results in a decrease of absorbance proportional to the concentration and antioxidant activity of the compounds itself. According to the chemical reactions involved, major antioxidant capacity assays can be roughly divided into two categories: hydrogen atom transfer (HAT) and single electron transfer (ET) reaction based assays. The majority of HAT assays apply a competitive reaction scheme, which antioxidant and substrate compete for thermally generated peroxyl radicals through the decomposition of azo compounds such as oxygen radical absorbance capacity (ORAC). ET-based assays measure the capacity of an antioxidant in the reduction of an oxidant, which changes colour when reduced. The degree of colour change is correlated with the sample antioxidant concentration life, the total phenols assay by Folin-Ciocalteu reagent (FCR). ORAC assay has been largely applied as a method of choice to quantify antioxidant capacity and it exists as database on combination with the total phenols assay. ORAC assay has found even broader application for measuring the antioxidant capacity of botanical samples (Prior \& Cao, 2000) and biological samples (Cao \& Prior, 1998). It consists of measuring the decrease in fluorescence of B- or R-phycoerythrin in the presence of 2,2' azobis(2-aminodinopropane) dihydrochloride and uses an area-under-curve technique for quantification. The 
measured antioxidant capacity of a sample depends on which technology and which free radical generator or oxidant is used in the measurement (Cao, Alessio, \& Cutler, 1993; Cao \& Cutler, 1993; Halliwell \& Gutteridge, 1995). The ORAC assay depends on the unique properties of phycoerythrins. Since they use peroxyl radicals, the most common radicals found in human body, ORAC measurements are more biologically relevant. Nevertheless, the length of inhibition time for ORAC assays is higher than that obtained with other assays, such DPPH and FC.

The measurement of the consumption of $\mathrm{DPPH}^{*}$ allows one to determine the intrinsic ability of a substance or a complex mixture to donate hydrogen atoms or electrons to this reactive species in a homogeneous system. This technique does not consider the partition in organized mediums or antioxidant mechanisms other than radical scavenging (Chaillou \& Nazareno, 2006). Considering the DPPH' radical and the donor molecule RH (antioxidant), the primary reaction (Fig. 3) is the formation of free radical $\mathrm{R}^{*}$ and the reduced form of DPPH'. The free radical produced can undergo further reactions which control the number of the molecules of DPPH reduced by one molecule of the reductant.

For the antioxidant capacity, one of the most frequently used methods is based on the generation of the highly stable chromophoric cation-radical of $\mathrm{ABTS}^{+}$, and the ability of the presumed antioxidant either to delay its appearance or to capture it and diminish its absorbance (Miller, Sampson, Candeias, Bramley, \& Rice-Evans, 1996). This enables determinations to be performed easily and quickly, allowing a considerable number of samples to be processed together and it provides very reliable results. Total phenols and polyphenols are usually quantified by employing Folin-Ciocalteu's reagent. This procedure is also employed in the wine industry, where gallic acid is usually selected as a standard. The FCR actually measures a sample reducing capacity, but this is not reflected in the name "total phenolic assay" (Huang et al., 2005). A recent report of using polyphenol oxidase for assaying total phenols in tea may be more specific to phenolic compounds (Stevanato, Fabris, $\&$ Momo, 2004). FCR is non-specific to phenolic compounds as it can be reduced by many non-phenolic compounds but react with phenolic compounds only under basic conditions. Even with the undefined chemical nature of FCR, the total phenols assay by FCR is convenient, sim-

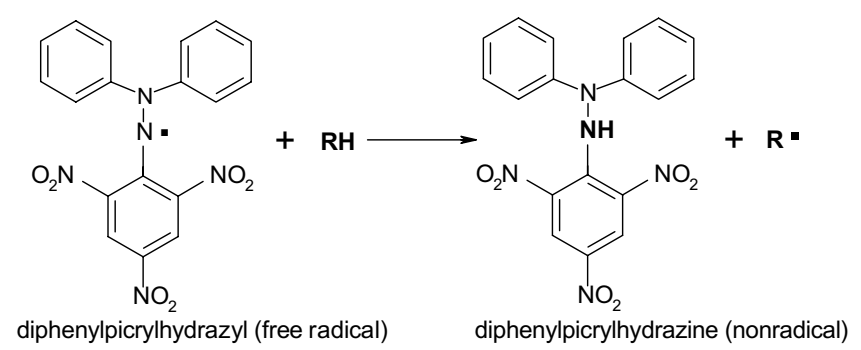

Fig. 3. Structure of DPPH and its reduction by the antioxidant RH. ple and reproducible and it is commonly accepted assay and routinely practiced in dietary antioxidant research laboratories throughout the world (Huang et al., 2005).

The main objective of this work was to determine the total content of phenolic compounds in different Terras Madeirenses table wines (red, rosé and white wines) produced in Madeira Island, Portugal, and to determine and compare the antioxidant capacity of these samples applying three commonly used spectrophotometric methods: $\mathrm{DPPH}^{\cdot}, \mathrm{ABTS}^{++}$and $P_{\mathrm{R}}$.

\section{Materials and methods}

\subsection{Wine samples}

For this study, we selected the most important and representative commercial table wines available in Madeira Island, which are five red wines, one rosé wine and from the 12 white wines we choose the most representative five white wines, produced according to standard procedures, were supplied by the Madeira Wine Institute (IVM). All samples were of 2005 vintage and all the analysis were carried out in triplicate.

\subsection{Chemicals}

2,2'-Azino-bis-(3-ethylbenzothiazoline-6-sulfonic acid) in the crystallized diammonium salt form (ABTS $\approx 98.0 \%$ ), Folin-Ciocalteu reagent (FC reagent), gallic acid monohydrate $(\geqslant 98.0 \%)$, potassium persulfate, 1,1-diphenyl-2picrylhydrazyl $\left(\mathrm{DPPH}^{*} \approx 90.0 \%\right)$ in free radical form, 6-hydroxy-2,5,7,8-tetramethylchloroman-2-carboxylic acid (Trolox), 2,2'-dipyridyl (bipyridine), trichloroacetic acid (TCA) and citric acid were obtained from Fluka. Sodium tartrate and iron chloride were supplied from Riedel de Haën, while sodium carbonate was from Panreac and methanol (99.9\% purity) from Sigma-Aldrich. All reagents and standards were prepared using Milli Q deionized water (Millipore, Bedford, USA).

\subsection{Equipment}

Absorbance measurements were recorded on a PerkinElmer Lambda 2 spectrophotometer. All samples were analyzed in $10 \mathrm{~mm}$ quartz cells at room temperature.

\subsection{Determination of total polyphenol content (TPC)}

The content of total phenolic compounds in wine samples was determined by the Folin-Ciocalteu's (FC) reagent (Minussi et al., 2003), using gallic acid as standard. This method is based on the reduction of a phosphowolframate-phophomolybdate complex by phenolics to blue reaction products. For the preparation of calibration curve, $1 \mathrm{ml}$ aliquots of $5,10,20,25$ and $50 \mathrm{mg} / 1$ aqueous gallic acid solutions were mixed with $0.025 \mathrm{ml} \mathrm{FC}$ reagent. Concerning the wines, to $1 \mathrm{ml}$ of wine sample (adequately 
diluted), $0.25 \mathrm{ml}$ of carbonate-tartarate solution $(20 \mathrm{~g}$ of $\mathrm{Na}_{2} \mathrm{CO}_{3}$ and $1.2 \mathrm{~g}$ of $\mathrm{Na}_{2} \mathrm{C}_{4} \mathrm{H}_{4} \mathrm{O}_{6} \cdot \mathrm{H}_{2} \mathrm{O}$ in $100 \mathrm{ml}$ of deionized water) and $0.025 \mathrm{ml}$ of Folin-Ciocalteu's reagent were added. The absorbance of the standards and samples was measured at $700 \mathrm{~nm}$ after $30 \mathrm{~min}$ of reaction at room temperature. The results were expressed as $\mathrm{mg}$ of gallic acid equivalents (GAE) $1^{-1}$. High reproducible results for standards $\left(r^{2}>0.9993\right)$ and samples were obtained. All determinations were performed in triplicate.

\subsection{Measurement of the antioxidant capacity}

The antioxidant capacity of wine samples in the reaction with stable $\mathrm{ABTS}^{+}$radical cation was determined according to Re et al. (1999), method with slight modifications. $\mathrm{ABTS}^{+}$was performed by the reaction of $2 \mathrm{mM}$ of $2,2-$ azino-bis-(ethylbenzothiazoline-6-sulfonic acid) diammonium salt (ABTS) with $70 \mathrm{mM}$ potassium persulfate in $50 \mathrm{ml}$ of phosphate buffered saline (PBS) (Baltrusaityte, Venskutonis, \& Ceksteryte, 2006). The mixture was left to stand in the dark at room temperature for $15-16 \mathrm{~h}$ before use. For the evaluation of the activity, the ABTS ${ }^{+}$ solution was diluted with PBS to obtain the absorbance of $0.800 \pm 0.030$ at $734 \mathrm{~nm}$. Then $12 \mu \mathrm{l}$ of wine sample was mixed with $3 \mathrm{ml}$ of $\mathrm{ABTS}^{+}$solution. The absorbance was read at room temperature during $20 \mathrm{~min}$. PBS solution was used as a blank sample. The percentage decrease of the absorbance at $734 \mathrm{~nm}$ was calculated by the formula $I=\left[\left(A_{\mathrm{B}}-A_{\mathrm{A}}\right) / A_{\mathrm{B}}\right] \times 100$, where $I=\mathrm{ABTS}^{+}$inhibition $\%, A_{\mathrm{B}}=$ absorbance of a blank sample $(t=0 \mathrm{~min})$, $A_{\mathrm{A}}=$ absorbance of a tested wine at the end of the reaction $(t=20 \mathrm{~min})$.

\section{6. $D P P H \cdot$ radical scavenging assay}

The changes in colour (from purple to a residual pale yellow colour) were measured at $515 \mathrm{~nm}$ on a UV/Visible light spectrophotometer. Free radical scavenging activity $\left(A_{\mathrm{AR}}\right)$ of the studied wines was determined using the DPPH' method proposed by Makris, Psarra, Kallithraka, and Kefalas (2003). An aliquot of adequately diluted samples $(1: 10$ with an ethanolic solution $-12 \%$ in $\mathrm{KCl} / \mathrm{HCl}$ $0.2 \mathrm{M}$ buffer, $\mathrm{pH} 2.0$ ) was added to $0.975 \mathrm{ml} \mathrm{DPPH}$ solution $(0.06 \mathrm{mM}$ in $\mathrm{MeOH})$ and vortexed. The absorbance of the remaining DPPH was determined after $60 \mathrm{~min}$ at $515 \mathrm{~nm}$ against methanol blank. The radical scavenging activity was calculated by the following formula: $A_{\mathrm{AR}}$ $(\mathrm{mM}$ TRE $)=0.699 \times \ln \left(\% \Delta A_{515}\right)-7.023$, as determined from the linear regression, after plotting $\ln \left(\% \Delta A_{515}\right)$ of known solutions of $\operatorname{Trolox}^{\circledR}$ against concentration (mM), where $\% \Delta A_{515}=\left[\left(A_{515(0)}-A_{515(60)}\right) / A_{515(0)}\right] \times 100, A_{515(0)}$ is the absorbance value measured at the beginning of the reaction and $A_{515(60)}$ is the absorbance value after $60 \mathrm{~min}$ of reaction.

The percentage of remaining $\mathrm{DPPH}^{\cdot}\left(\% \mathrm{DPPH}_{\mathrm{REM}}^{-}\right)$ was calculated as follows: $\% \mathrm{DPPH}_{\mathrm{REM}}=\left[\mathrm{DPPH}^{\cdot}\right]_{T=60} /$ $[\mathrm{DPPH} \cdot]_{T=0}$.
The percentage of remaining $\mathrm{DPPH}^{\cdot}$ against the standard concentration was then plotted to obtain the amount of antioxidant necessary to decrease the initial $\mathrm{DPPH}^{\circ}$ concentration by $50 \%$. The time needed to reach the steady state to $\mathrm{EC}_{50}$ concentration $\left(T_{\mathrm{EC}_{50}}\right)$ was calculated graphically. Taking into account that both, $\mathrm{EC}_{50}$ and $T_{\mathrm{EC}_{50}}$, affect the antiradical capacity, a new parameter, antioxidant efficiency (AE), which combines these two factors, was defined: $\mathrm{AE}=1 / \mathrm{EC}_{50} T_{\mathrm{EC}_{50}}$ (Sánchez-Moreno, Larrauri, $\&$ Saura-Calixto, 1998).

\subsection{Measurement of the reduction power $\left(P_{R}\right)$}

For the determination of the reducing power of wines, a protocol based on the ferric reducing/antioxidant power (FRAP) assay was developed (Pullido, Bravo, \& SauraCalixto, 2000). The ferrous $\left(\mathrm{Fe}^{2+}\right)$ ion produced from the redox reaction forms a coloured product with 2,2'-dipyridyl which has a $\lambda_{\max }$ at $525 \mathrm{~nm}$ (Makris et al., 2003). An aliquot of $0.25 \mathrm{ml}$ of wine appropriately diluted was mixed with $0.25 \mathrm{ml}$ of $3 \mathrm{mM} \mathrm{FeCl}_{3}$ in $5 \mathrm{mM}$ citric acid. The mixture was vortexed and incubated at $50{ }^{\circ} \mathrm{C}$ in a water bath for $20 \mathrm{~min}$. Following this, $4.5 \mathrm{ml}$ of $0.5 \%$ 2,2'-dipyridyl in $1.2 \%$ TCA was added, the mixture was vortexed, and after $5 \mathrm{~min}$ the absorbance was read at $525 \mathrm{~nm}$. Reducing power $\left(P_{\mathrm{R}}\right)$ was expressed as quercetin equivalents $(\mathrm{mM}$ QE) from the following equation: $P_{\mathrm{R}}(\mathrm{mM} \quad \mathrm{QE})=$ $\left(0.632 \times A_{525}-0.1147\right) \times F_{\mathrm{D}}$ as determined from linear regression, where $F_{\mathrm{D}}$ is the dilution factor.

\section{Results and discussion}

The total phenolic content (TPC) and the antioxidant capacity of 12 commercial wines, five red wines, one rosé wine and five white wines were analyzed and compared. The results of TPC, $P_{\mathrm{R}}, \mathrm{DPPH}^{\cdot}$ and $\mathrm{ABTS}^{+}$inhibition for different wine types are summarized in Tables 1 and 2 and in Figs. 4, 6 and 7, respectively.

\subsection{Total phenol content}

The amounts of phenolic materials vary considerably in different types of wines, depending on the grape variety, environmental factors in the vineyard and the wine processing techniques (Villaño, Fernández-Pachón, Troncoso, \& García-Parrilla, 2004). Our results confirm a variation in phenolic content among wine samples tested. These results are in agreement with those available in the literature (Campodonico, Barberi, Pizarro, Sotomayor, \& Lissy, 1998; Frankel, Waterhouse, \& Teissedre, 1995; Hurtado et al., 1997; Kanner, Frankel, Granit, German, \& Kinsella, 1995; Sato et al., 1996; Simonetti, Pietta, \& Testolin, 1997). The presence of high concentrations of gallic acid in red wines would be expected since this phenolic acid is principally formed by hydrolysis of flavonoid gallate esters, which are largely absent in white wines, due to the lack of skin extraction. The content of phenolic compounds 
Table 1

Total phenolic content (TPC) and total antioxidant capacity (TAC) determined in Terras Madeirenses Portuguese wine samples (average $\pm \%$ RSD) $(n=3)$

\begin{tabular}{|c|c|c|c|}
\hline Wine samples & Varietal composition & $\mathrm{TPC}(\mathrm{mg} / \mathrm{l})^{\mathrm{a}}$ & $\mathrm{TAC}\left(\mathrm{mg} / \mathrm{l}^{\mathrm{a}}\right.$ \\
\hline VT-1 (red) & Tinta Negra Mole & $1827 \pm 8.1$ & $732 \pm 4.2$ \\
\hline VT-2 (red) & Tinta Negra Mole, Cabernet Sauvignon, Merlot & $1871 \pm 8.2$ & $793 \pm 5.7$ \\
\hline VT-3 (red) & Tinta Negra Mole, Cabernet Sauvignon, Merlot, Complexa & $1853 \pm 8.1$ & $903 \pm 8.1$ \\
\hline VT-5 (red) & Touriga Nacional, Merlot, Cabernet Sauvignon & $1724 \pm 7.9$ & $1105 \pm 5.7$ \\
\hline VR-1 (rosé) & Tinta Negra Mole & $665 \pm 2.1$ & $502 \pm 2.4$ \\
\hline VB-1 (white) & Verdelho & $370 \pm 5.8$ & $344 \pm 3.6$ \\
\hline VB-4 (white) & Verdelho, Arnburger & $389 \pm 5.1$ & $508 \pm 4.9$ \\
\hline VB-5 (white) & Malvasia & $434 \pm 3.5$ & $431 \pm 4.9$ \\
\hline
\end{tabular}

${ }^{\text {a }}$ Values expressed as mg of gallic acid equivalents (GAE) $1^{-1}$, bold character indicates the main variety.

Table 2

Antioxidant properties (average $\pm \% \mathrm{RSD}, n=3$ ) of the wines examined

\begin{tabular}{|c|c|c|c|c|c|}
\hline Wine samples & Main variety & $A_{\mathrm{AR}}(\mathrm{mM} \text { TRE })^{\mathrm{a}}$ & $\% \mathrm{DPPH}_{\text {REM }}$ & $\%$ ABTS (inhibition) & $P_{\mathrm{R}}(\mathrm{Mm} \mathrm{QE})^{\mathrm{b}}$ \\
\hline VT-1 (red) & TNM & $0.67 \pm 1.5$ & $10.47 \pm 5.2$ & $42.90 \pm 3.2$ & $3.59 \pm 2.7$ \\
\hline VT-2 (red) & TNM & $0.58 \pm 5.3$ & $23.75 \pm 4.9$ & $45.34 \pm 4.6$ & $3.45 \pm 4.1$ \\
\hline VT-3 (red) & TNM & $0.56 \pm 2.2$ & $25.59 \pm 3.5$ & $49.60 \pm 2.8$ & $3.62 \pm 6.7$ \\
\hline VT-5 (red) & T. Nacional & $0.71 \pm 4.2$ & $4.86 \pm 7.3$ & $57.00 \pm 5.1$ & $3.86 \pm 2.5$ \\
\hline VR-1 (rosé) & TNM & $0.24 \pm 2.2$ & $87.90 \pm 5.4$ & $36.25 \pm 1.7$ & $1.37 \pm 6.3$ \\
\hline VB-1 (white) & Verdelho & $0.06 \pm 4.5$ & $38.39 \pm 6.2$ & $41.13 \pm 4.3$ & $0.58 \pm 5.8$ \\
\hline VB-4 (white) & Verdelho & $0.05 \pm 3.4$ & $51.87 \pm 5.4$ & $53.78 \pm 6.1$ & $0.60 \pm 8.2$ \\
\hline VB-5 (white) & Malvasia & $0.08 \pm 1.8$ & $13.47 \pm 2.1$ & $48.06 \pm 5.0$ & $0.67 \pm 6.6$ \\
\hline
\end{tabular}

For the antiradical activity $\left(A_{\mathrm{AR}}\right)$ measurements, samples were diluted 1:10.

a Antiradical activity (Trolox equivalents - TRE).

${ }^{\mathrm{b}}$ Reducing power (quercetin equivalents - QE).

a

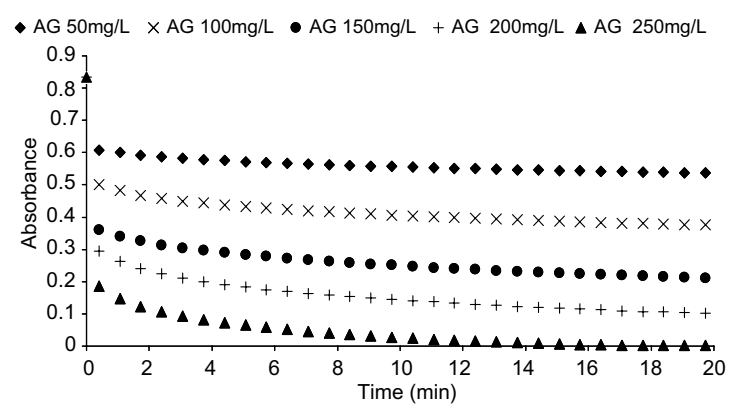

C

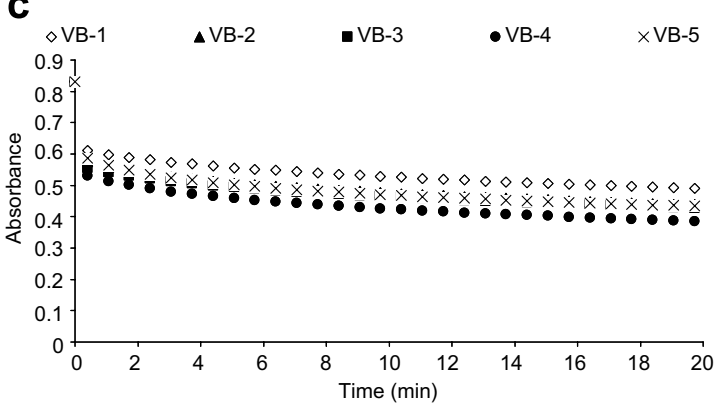

b

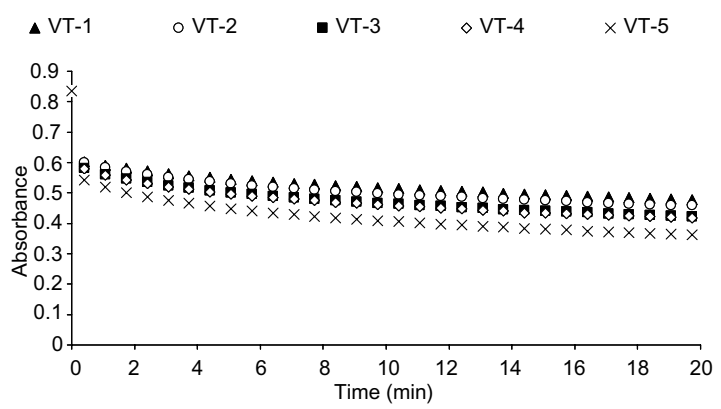

d

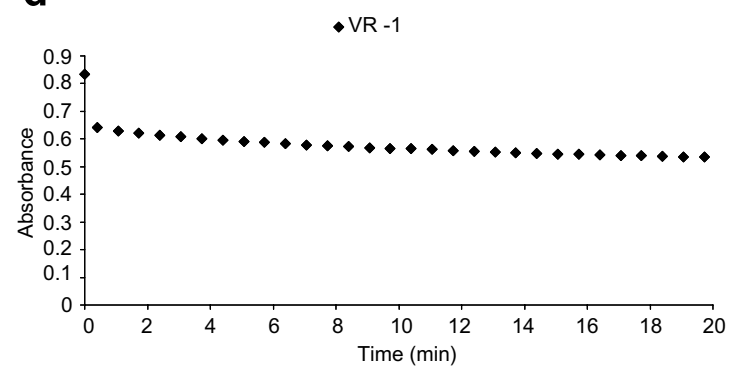

Fig. 4. ABTS behavior in the presence of (a) antioxidant; (b) red wine samples; (c) white wine samples and (d) Madeira table rosé wine sample. 
(free and total) determined by the FC method for the different analyzed wines is shown in Table 1 . The total polyphenol content in red wine was significantly higher than in rosé and white wine ( $p<0.05$ for both cases). All red wines

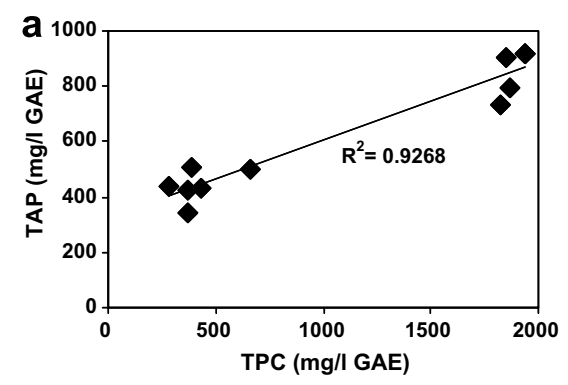

had phenolic concentrations higher than $1500 \mathrm{mg} / \mathrm{l}$. The content of phenolics decrease in the order: red wine, rosé and white wine, with the lowest values found in VB3 $(282 \mathrm{mg} / \mathrm{l})$ and VB1 (370 mg/l) wines (Table 1). The relative

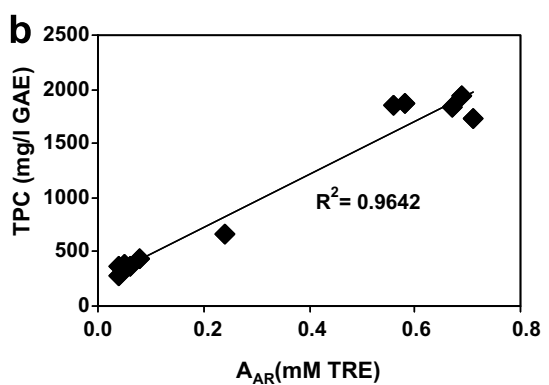

Fig. 5. Linear correlation plot of the total polyphenol content (TPC) as a function of (a) total antioxidant potential (TAP), and (b) antiradical activity $A_{\mathrm{AR}}$.
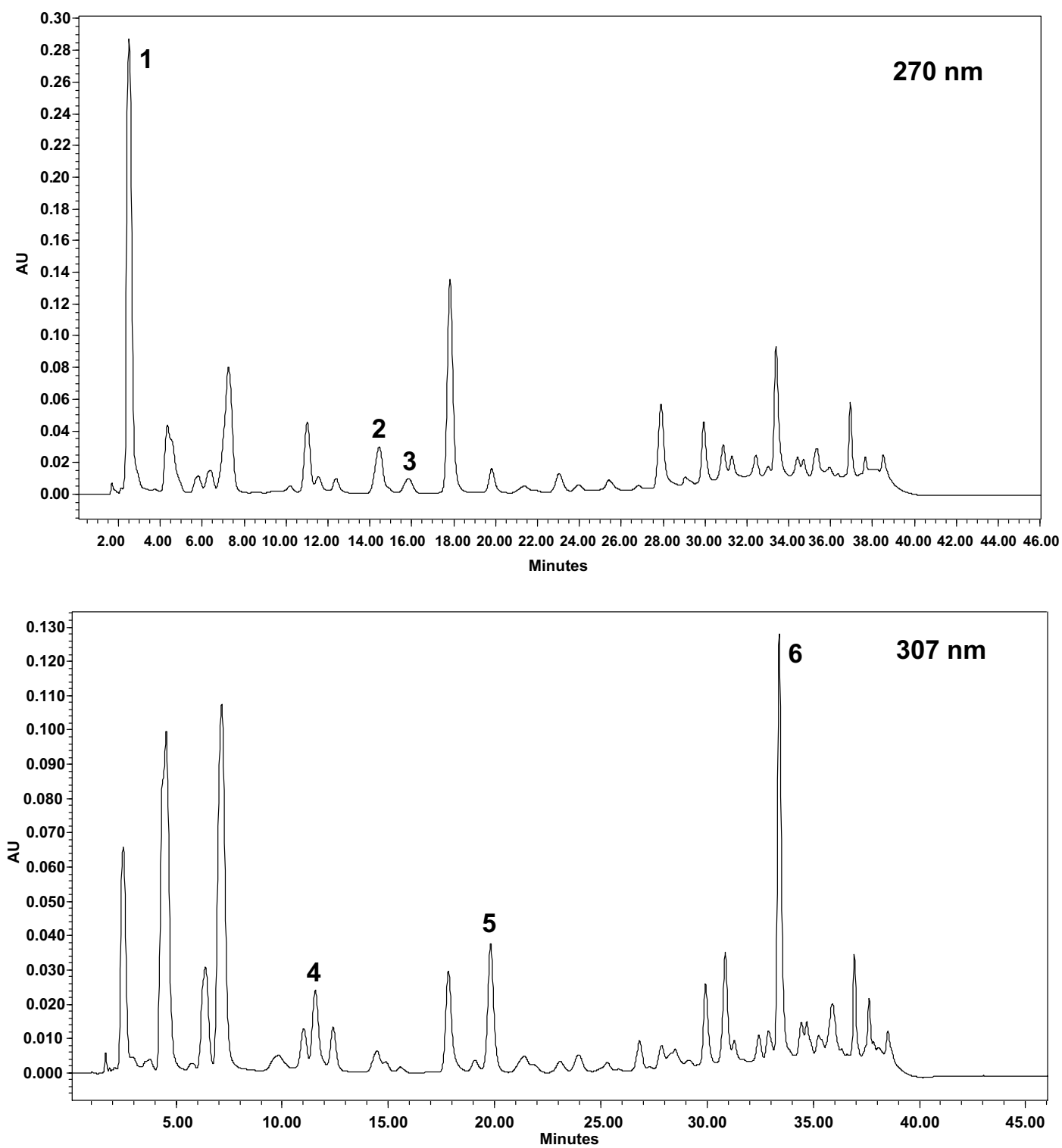

Fig. 6. HPLC-DAD chromatogram of a wine sample detected at $270 \mathrm{~nm}$ and $307 \mathrm{~nm}$. Peak identification: 1: gallic acid; 2: syringic acid; 3:(-)-epicatechin; 4: cafeic acid; 5 p-coumaric acid; 6:trans-resveratrol. 
values determined from regression equation of calibration curve $\left(y=0.0493 x-0.0633 ; r^{2}=0.9993\right)$ and expressed in gallic acid equivalents (GAE) varied between $1724 \mathrm{mg} / \mathrm{l}$ (VT5) and $1936 \mathrm{mg} / 1$ (VT4), averaging $1842 \mathrm{mg} / 1$, for the red wines and $282 \mathrm{mg} / \mathrm{l}$ (VB3) to $434 \mathrm{mg} / 1$ (VB5), averaging $369 \mathrm{mg} / 1$ for the white wines. For rosé wine we obtained $665 \mathrm{mg} / \mathrm{l}$ (GAE). The highest content of phenolics was found in VT4 and the lowest in the VT5 wine. VT2 and VT1 also contained a high content of phenolic compounds.

\subsection{Antioxidant assays}

\subsubsection{Determination of the antioxidant capacity}

The total antioxidant capacity (TAC) of wine samples was determined by the bleaching of pre-formed ABTS radical cations. The $\mathrm{ABTS}^{+}$reagent was very unstable, and it was slowly degraded at the given experimental conditions. The $\mathrm{ABTS}^{+}$behaviour in the presence of an antioxidant (gallic acid) is shown in Fig. 4a. The addition of free radical-scavengers to a solution containing ABTS-derived radical cations leads to a decrease in the absorbance of the sample at $734 \mathrm{~nm}$ as is shown in Fig. 4b-d. Table 1 shows that red wines presented a substantial antioxidant capacity. The values varied from $732 \mathrm{mg} / 1$ (VT1) to $1105 \mathrm{mg} / 1$ (VT5) averaging $891 \mathrm{mg} / 1$ for the red wines, $344 \mathrm{mg} / 1$ (VB1) to $508 \mathrm{mg} / \mathrm{l}$ (VB4) averaging $429 \mathrm{mg} / 1$ for the white wines and $502 \mathrm{mg} / 1$ (GAE) for rosé wine. Total phenolic content and antioxidant activity of studied wines were highly correlated $\left(R^{2}=0.9268\right.$; Fig. $\left.5 \mathrm{a}\right)$ providing strong evidences that the predominant source of antioxidant activity derives from phenolic compounds in wine.

A parallel study developed in our laboratory showed that the major antioxidant compounds present in Terras
Madeirenses wines include gallic acid, (+)-catechin, (-)epicatechin, $p$-coumaric acid and caffeic acid. Fig. 6 shows the chromatogram profile (at 270 and $307 \mathrm{~nm}$ ) obtained for the determination of the phenolic compounds in VT3 wine.

\subsubsection{DPPH radical-scavenging activity}

The measurement of the consumption of $\mathrm{DPPH}^{\cdot}$ radical allows one to determine exclusively the intrinsic ability of a substance to donate hydrogen atoms or electrons to this reactive species in a homogeneous system. The method is based on the reduction of alcoholic $\mathrm{DPPH}^{\cdot}$ solution in the presence of a hydrogen-donating antioxidant due to the formation of non-radical form DPPH-H (Duan, Zhang, Li, \& Wang, 2006) by the reaction (Fig. 3). A blue-violet colour changes gradually to green and yellow and a decrease in absorbance at $515 \mathrm{~nm}$ is monitored during the reaction. The kinetic behaviour of the radical disappearance in the presence of Trolox and different wine types expressed as absorbance at $515 \mathrm{~nm}$ vs. time is presented in Fig. 7a. The reaction rate characterizes the reactivity and it can be calculated as a slope of the reaction kinetics at the beginning of the reaction $(t \approx 0)$. The $\ln \left(\% \Delta A_{515}\right)$ value of a methanolic DPPH. solution has been found to decrease linearly in response to increasing amounts of Trolox. The DPPH kinetic behaviour in the different wine types under study is presented in Fig. 7b-d. The $A_{\mathrm{AR}}$ value of the wines tested was found to vary from $0.56 \mathrm{mM}$ (VT3) to $0.71 \mathrm{mM}$ (VT5) averaging $0.65 \mathrm{mM}$ for the red wines, $0.04 \mathrm{mM}$ (VB2 and VB3) to $0.08 \mathrm{mM}$ (VB5) averaging $0.06 \mathrm{mM}$ for the white wines and $0.24 \mathrm{mM}$ (TRE) the for rosé wines. VT4 wine which had the highest mean TPC concentration also had the highest mean $A_{\mathrm{AR}}$. In contrast, wines from VB3, which had the lowest mean TPC also,
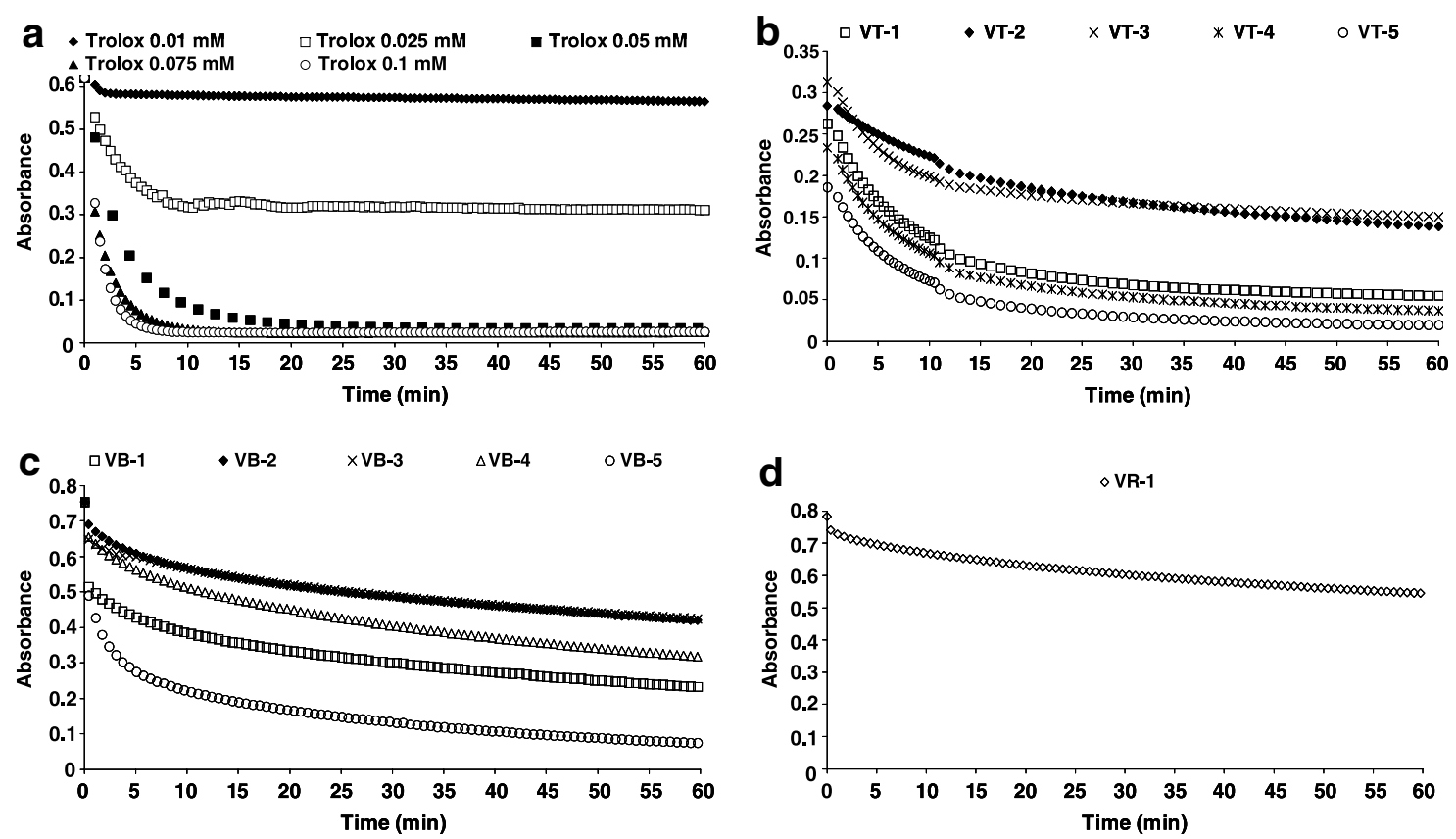

Fig. 7. DPPH kinetics behavior in the presence of (a) Trolox; (b) red wine samples; (c) white wine samples and (d) rosé wine. 

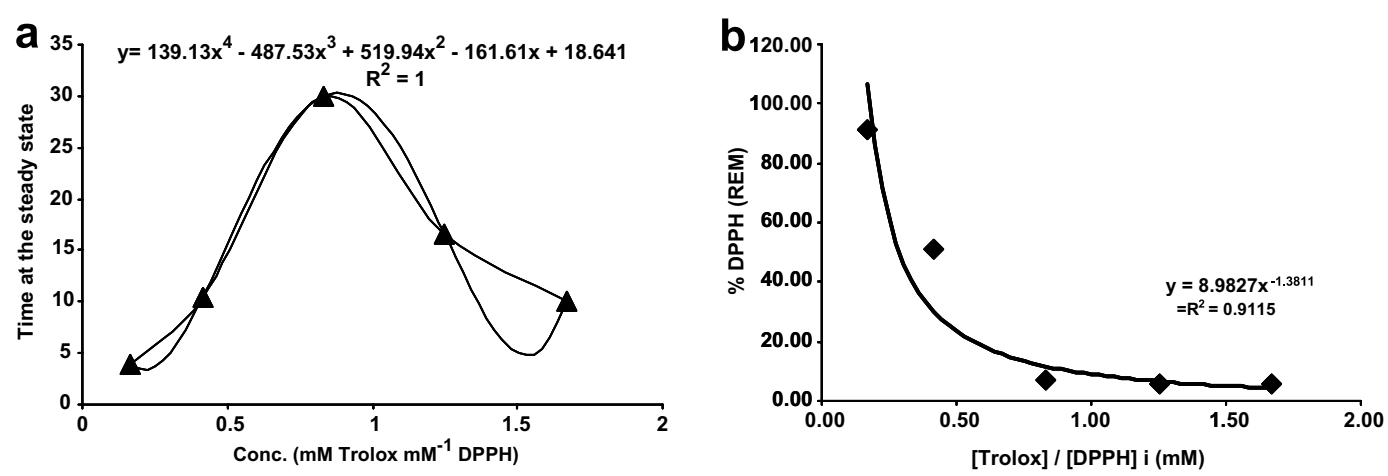

Fig. 8. The percentage remaining of free DPPH radical in the presence of (a) different concentration of antioxidant, and (b) graph that allow to determine the time needed to reach the steady state to $\mathrm{EC}_{50}$ concentration.
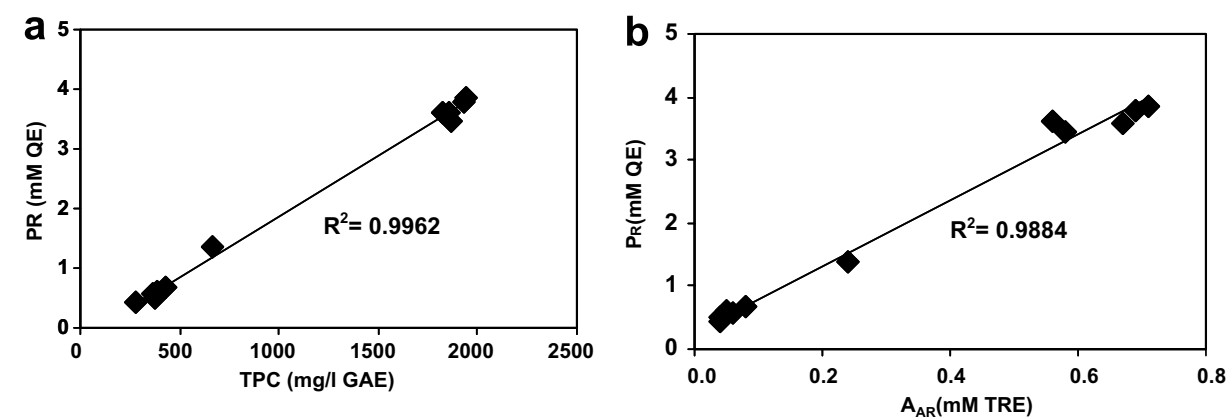

Fig. 9. Correlation between reducing power $\left(P_{\mathrm{R}}\right)$ and (a) total phenolic content (TPC); (b) antiradical activity $\left(A_{\mathrm{AR}}\right)$

exhibit the lowest mean $A_{\mathrm{AR}}$ value. The correlation with TPC contents was found to be high $\left(R^{2}=0.964\right.$, Fig. $\left.5 b\right)$, suggesting that the antiradical activity of wines may be correlated with the total phenolic compounds.

A previous antioxidant kinetic classification based on the time to reach a steady state (Brand-Williams, Cuvelier, \& Berset, 1995) was used to calculate $\mathrm{EC}_{50}$ and the time needed to reach a steady state $T_{\mathrm{EC}_{50}}$, at the concentration corresponding to $\mathrm{EC}_{50}$. The lower the $\mathrm{EC}_{50}$ the higher the antioxidant activity of a compound is. This parameter was obtained by plotting the times at the steady state against the concentration of antioxidant as illustrated in Fig. 8a. The relationship between the $T_{\mathrm{EC}_{50}}$ and the antioxidant concentration followed a fourth order model with $R^{2}=1$. The percentage of the remaining $\mathrm{DPPH}^{\cdot}$ concentration against the antioxidant concentration is also shown in Fig. 8b.

\subsection{Reducing power}

The antioxidant properties of many compounds are directly related to their reducing power. The analyses showed that $P_{\mathrm{R}}$ varied within a wide range, which is an indication that the reducing power is dependent on the total polyphenolic content. $P_{\mathrm{R}}$ thus determined ranged from $3.45 \mathrm{mM}$ to $3.86 \mathrm{mM}$ averaging $3.66 \mathrm{mM}$ for the red wines, $0.44-0.67 \mathrm{mM}$ averaging $0.56 \mathrm{mM}$ for the white wines and $1.37 \mathrm{mM}(\mathrm{QE})$ for the rosé wines as shown in Table 2.
It can be observed that the content of phenolics correlates with their reducing power (e.g. correlation coefficient between data of $P_{\mathrm{R}}$ and total phenolic compounds is 0.9962, Fig. 9a). Similarly a high correlation was observed between antiradical activity and reducing power ( $R^{2}=0.9884$; Fig. 9b) confirming that phenolic compounds are likely to contribute to the radical scavenging activity of these wines.

\section{Conclusions}

In summary, it was verified that the red wines have higher TPC levels than white and rosé wines and the same is obtained for antiradical activity and antioxidant capacity. Total phenolics and antioxidant activity were highly correlated. There was a significant difference in total phenolics or antioxidants between red and white wine samples used in the studies. The determination of antiradical activity by the DPPH method using Trolox as standard, could be a practical and simple measurement to evaluate the characteristics of different Madeira Table wines.

The addition of different amounts of antioxidant to the DPPH solution induced a rapid decrease in the optical density at $515 \mathrm{~nm}$. The results of investigation show that the higher the concentration of antioxidant is, the lower the amount of remaining DPPH ${ }^{*}$ and the higher the free radical scavenging activity. The same is observed for the ABTS ${ }^{+}$ radical cation. 
Overall, there was no significant difference in total phenolics between red wines. These wines had significantly higher phenolic levels than the rosé and white wines, and consequently exhibit the highest antioxidant power.

\section{Acknowledgements}

This research work was supported by FEDER, Program INTERREG IIIB (Project ANTIVINMAC). The authors are grateful to Instituto do Vinho Madeira and Madeira Wine Company for the supply of the samples used in the study.

\section{References}

Alonso, A. M., Domínguez, C., Guillén, D. A., \& Barroso, C. G. (2002). Determination of antioxidant power of red and white wines by a new electrochemical method and its correlation with polyphenolic content. Journal of Agricultural and Food Chemistry, 50(11), 3112-3115.

Baltrusaityte, V., Venskutonis, P. R., \& Ceksteryte, V. (2006). Radical scavenging activity of different floral origin honey and beebread phenolic extracts. Food Chemistry, 76, 270-283.

Brand-Williams, W., Cuvelier, M. E., \& Berset, C. (1995). Use of a free radical method to evaluate antioxidant activity. Lebensmittel-Wissenschaft \& Technologie, 28(11), 25-30.

Campodonico, P., Barberi, E., Pizarro, M., Sotomayor, C. P., \& Lissy, E. A. (1998). A comparison between total phenol content of wines and their TRAP values measured by the bleaching of ABTS radical cations. Boletin de la Sociedad Chilena de Quimica, 43, 281-285.

Cao, G., Alessio, H. M., \& Cutler, R. G. (1993). Oxygen-radical absorbance capacity assay for antioxidants. Free Radical Biology and Medicine, 14, 303-311.

Cao, G., \& Cutler, R. G. (1993). High concentrations of antioxidants may not improve defense against oxidative stress. Archives of Gerontology and Geriatrics, 17, 189-201.

Cao, G., \& Prior, R. L. (1998). Comparison of different analytical methods for assessing total antioxidant capacity of human serum. Clinical Chemistry, 44, 1309-1315.

Cao, G., \& Prior, R. L. (2000). Red wine in moderation: Potential health benefits independent of alcohol. Nutrition in Clinical Care, $3(2), 76-82$.

Chaillou, L. L., \& Nazareno, M. A. (2006). New method to determine antioxidant activity of polyphenols. Journal of Agricultural and Food Chemistry, 54, 8397-8402.

Duan, X. J., Zhang, W. W., Li, X. M., \& Wang, B. G. (2006). Evaluation of antioxidant property of extract and fractions obtained from a red alga, Polysiphonia urceolata. Food Chemistry, 95(1), 37-43.

Estruch, R. (2000). Wine and cardiovascular diseases. Food Research International, 33(3), 219-226.

Flamini, R. (2003). Mass spectrometry in grape and wine chemistry. Part I: Polyphenols. Mass Spectrometry Reviews, 22, 218-250.

Frankel, E. N., Waterhouse, A. L., \& Teissedre, P. L. (1995). Principal phenolic phytochemicals in selected California wines and their antioxidant activity in inhibiting oxidation of human low-density lipoproteins. Journal of Agricultural and Food Chemistry, 43, 890894.

Guendez, R., Kallithraka, S., Makris, D. P., \& Kefalas, P. (2005). Determination of low molecular weight polyphenolic constituents in grape (Vitis vinifera sp.) seed extracts: Correlation with antiradical activity. Food Chemistry, 89, 1-9.

Halliwell, B., \& Gutteridge, J. M. C. (1995). The definition and measurement of antioxidants in biological systems. Free Radical Biology and Medicine, 18, 125-126.
Harbone, J. B. (1980). Plant phenolics. In E. A. Bell \& B. V. Charlwood (Eds.). Encyclopedia of plant physiology, secondary plant products (Vol. 8, pp. 329-395). New York: Springer-Verlag, Berlin Heidelberg.

Haslam, E. (1996). Natural polyphenols (vegetable tannins) as drug and medicine: Possible modes of action. Journal of Natural Products, 59, 205-215.

Huang, D., Ou, B., \& Prior, R. L. (2005). The chemistry behind antioxidant capacity assays. Journal of Agricultural and Food Chemistry, 53, 1841-1856.

Hurtado, I., Caldú, P., Gonzalo, A., Ramon, J. M., Mínguez, S., \& Fiol, C. (1997). Antioxidative capacity of wine on human LDL oxidation in vitro: Effect of skin contact in winemaking of white wine. Journal of Agricultural and Food Chemistry, 45(4), 1283-1289.

Kanner, J., Frankel, E., Granit, R., German, B., \& Kinsella, J. E. (1995). Natural antioxidants in grapes and wines. Journal of Agricultural and Food Chemistry, 42(1), 64-69.

Makris, D. P., Kallithraka, S., \& Kefalas, P. (2006). Flavonols in grapes, grape products and wines: Burden, profile and influential parameters. Journal of Food Composite Analysis, 19, 396-404.

Makris, D. P., Psarra, E., Kallithraka, S., \& Kefalas, P. (2003). The effect of polyphenolic composition as related to antioxidant capacity in white wines. Food Research International, 36, 805-814.

Miller, J. N., Sampson, J., Candeias, L. P., Bramley, P. M., \& Rice-Evans, C. A. (1996). Antioxidant activities of carotenes and xanthophylls. FEBS Letter, 384(3), 240-242.

Minussi, R. C., Rossi, M., Bologna, L., Cordi, L., Rotilio, D., Pastore, G. M., et al. (2003). Phenolic compounds and total antioxidant potential of commercial wines. Food Chemistry, 82, 409-416.

Monagas, M., Bartolomé, B., \& Gómez-Cordovés, C. (2005). Updated knowledge about the presence of phenolic compounds in wine. Critical Reviews in Food Science Nutrition, 45, 85-118.

Prior, R. L., \& Cao, G. H. (2000). Analysis of botanicals and dietary supplements for antioxidant capacity. A review. Journal of $A O A C$ International, 83(4), 950-956.

Psarra, E., Makris, D. M., Kallithraka, S., \& Kefalas, P. (2002). Evaluation of the antiradical and reducing properties of selected Greek white wines: Correlation with polyphenolic composition. Journal of the Science of Food and Agriculture, 82(9), 1014 1020.

Pullido, R., Bravo, L., \& Saura-Calixto, F. (2000). Antioxidant activity of dietary polyphenols as determined by a modified ferric reducing/ antioxidant power assay. Journal of Agricultural and Food Chemistry, 48(8), 3396-3402.

Renaud, S., \& De Lorgeril, M. (1992). Wine, alcohol, platelets, and the French paradox for coronary heart disease. The Lancet, 339(880), 1523-1526.

Re, R., Pellegrini, N., Proteggente, A., Pannala, A., Yang, M., \& RiceEvans, C. A. (1999). Antioxidant activity applying an improved ABTS radical cation decolourization assay. Free Radical Biology and Medicine, 26(9-10), 1231-1237.

Sánchez-Moreno, C., Larrauri, J. A., \& Saura-Calixto, F. (1998). A procedure to measure the antiradical efficiency of polyphenols. Journal of Agricultural and Food Chemistry, 76(2), 270-276.

Sato, M., Ramarathnam, N., Suzuki, Y., Ohkubo, T., Takeuchi, M., \& Ochi, H. (1996). Varietal differences in the phenolic content and superoxide radical scavenging potential of wines from different sources. Journal of Agricultural and Food Chemistry, 44(1), 37-41.

Simonetti, P., Pietta, P., \& Testolin, G. (1997). Polyphenol content and total antioxidant potential of selected Italian wines. Journal of Agricultural and Food Chemistry, 45(4), 1152-1155.

Stevanato, R., Fabris, S., \& Momo, F. (2004). Enzymatic method for the determination of total phenolic content in tea and wine. Agricultural Food Chemistry, 52, 6287-6293.

Stratil, P., Klejdus, B., \& Kubáñ, V. (2006). Determination of total content of phenolic compounds and their antioxidant activity in vegetables evaluation of spectrophotometric methods. Journal of Agricultural and Food Chemistry, 54, 607-616. 
Villaño, D., Fernández-Pachón, M. S., Moyá, M. L., Troncoso, A. M., \& García-Parrilla, M. C. (2007). Radical scavenging ability of polyphenolic compounds towards DPPH free radical. Talanta, 71, 230-235.

Villaño, D., Fernández-Pachón, M. S., Troncoso, A. M., \& GarcíaParrilla, M. C. (2004). The antioxidant activity of wines determined by the $\mathrm{ABTS}^{+}$method: Influence of sample dilution and time. Talanta, 64(2), 501-509.

Villaño, D., Fernández-Pachón, M. S., Troncoso, A. M., \& GarcíaParrilla, M. C. (2006). Influence of enological practices on the antioxidant activity of wines. Food Chemistry, 95, 394-404. 